\title{
ESTUDO MICRO-MESOSCÓPICO DA PAREDE LATERAL DO SEIO CAVERNOSO HUMANO
}

\author{
RENATO PAULO CHOPARD*, GUILHERME A. LUCAS**, ALESSANDRA VENOSA***
}

RESUMO - Os autores estudam as estruturas contidas no seio cavemoso humano, tanto em seu interior como na sua parede lateral, através de cortes frontais seriados espessos. Mostram a importância desta parede que é frequentemente usada como via de acesso cirúrgico às afecçōes presentes nesta estrutura venosa da dura-máter

PALAVRAS-CHAVE: seio cavernoso, meninges, dura-máter craniana.

Human cavernous sinus: micro-mesoscopic study of the lateral wall

ABSTRACT - The authors studied the structures of human cavernous sinus in its interior as well as on the lateral wall, utilizing thick, frontal, sequential sections. They show the significance of this wall, frequently used as surgical accessway to diseases encountered within this venous structure of the dura-mater.

KEY WORDS: cavemous sinus, meninges, dura mater.

Desde suas primeiras descriçōes ${ }^{13,25}$, o seio cavernoso tem despertado a atenção de diversos autores, notadamente no que diz respeito às suas relações com a artéria carótida interna e sua sintopia com os nervos cranianos III, IV e VI e a divisão oftálmica do V nervo craniano (V1). Descrições contraditórias são encontradas quanto à parede lateral do seio cavernoso e suas relações com estruturas, inclusas ou nāo em seu interior. Com a introdução de técnicas de microcirurgia e $o$ desenvolvimento de novos procedimentos neurocirúrgicos, surgiu um conhecimento mais acurado do seio cavernoso, notadamente de suas paredes laterais ${ }^{1,5,10,12,22,26}$. Textos clássicos de anatomia ${ }^{3,6,14,16,19,23}$ descrevem os nervos III, IV e V1 como estruturas envolvidas na parede lateral do seio, enquanto a carótida interna e o nervo VI estāo localizados na cavidade do seio. Autores ${ }^{11,15}$, descrevem a parede lateral com duas camadas: uma superficial e outra profunda. Esta última forma um septo na cavidade do seio e o divide em dois compartimentos: um medial, extenso e profundo, contendo a carótida intema e o nervo abducente; um outro compartimento mais estreito, lateral ao septo. Os nervos III, IV e V1 correm no interior do septo e nāo na camada superficial. Harris \& Rhoton ${ }^{7}$ e Rhoton et al. ${ }^{12}$ reconhecem duas aberturas durais na parede lateral do seio cavernoso, descrevendo também o curso e relaçð̄es dos nervos III, IV e V1 quando percorrem a parede dural. Mc Grath concluiu que os nervos III, IV e V1 não correm na parede dural lateral, ao contrário do que afirmam outros autores ${ }^{4,17,20}$, ou seja,

Estudo realizado no Departamento de Anatomia do Instituto de Ciências Biomédicas (ICB) da Universidade de São Paulo (USP): *Professor do Departamento de Anatomia, ICB/USP; **Mestrando, Departamento de Anatomia, ICB/USP; ***Médica Residente, Hospital das Clínicas da Facubdade de Medicina da USP (FMUSP). Aceite: 15-maio-1996.

Dr. Renato Paulo Chopard - Departamento de Anatomia, Instituto de Ciências Biomédicas, Universidade de Såo Paulo - Cidade Universitária Armando Salles de Oliveira, Edifício Biomédicas III - Av Lineu Prestes 2415 - 05508-900 São Paulo SP - Brasil. 
estes nervos passam na parede lateral entre um endotélio e a dura-máter. Autores ${ }^{2,21,24}$ consideram que o nervo craniano VI se localiza na parede lateral junto com os outros nervos. Diferenças de descrições são também estabelecidas quanto à presença ou não da divisão maxilar do trigêmio (V2) e do gânglio trigeminal na parede lateral. Taptas ${ }^{18}$ não aceita que os nervos e a carótida interna perfurem a dura-máter, mas que estejam envolvidos num estojo. Parkinson' não acredita na existência de um seio venoso nesta área, se a compararmos com a estrutura geral dos outros seios venosos intracranianos. Sugere a denominação de espaço lateral selar; este espaço paraselar estaria incluso entre duas camadas de dura-máter e conteria os nervos cranianos adjacentes, alguns nervos simpáticos, veias e tecido gorduroso ao redor da carótida interna e de seus ramos. Admite ele a existência de importante espaço triangular entre os nervos II e IV, acima, e os nervos V e VI, abaixo, que convergem em direçăo à fissura orbitária superior.

Como as descrições são bastante contraditórias, nos propusemos a estudar esta região através de cortes seriados espessos, método pouco utilizado por outros pesquisadores.

\section{MATERIAL E MÉTODO}

Foram utilizadas, para a realização deste estudo, 20 peças anatômicas de adultos jovens de ambos os sexos, obtidas no SVOC (Serviço de Verificação de Óbitos da Capital), Departamento de Anatomia Patológica da FMUSP. Os blocos continham a sela túrcica e o seio cavemoso, tomando-se, na sua obtenção, cuidado para não lesar as estruturas anatômicas contidas tanto no interior do seio como em sua parede lateral.

Cinco desses blocos foram separados para disseç̧ão sob lupa (FAPESP-91/2772-0) da parede lateral do seio cavernoso e de suas estruturas adjacentes. As restantes 15 peças foram reduzidas, obtendo-se blocos menores com os seguintes limites: anterior, um milímetro à frente dos processos clinoides anteriores, incluindo o nervo óptico e seu canal; posterior, um milímetro aquém dos processos clinoides posteriores; inferior, até

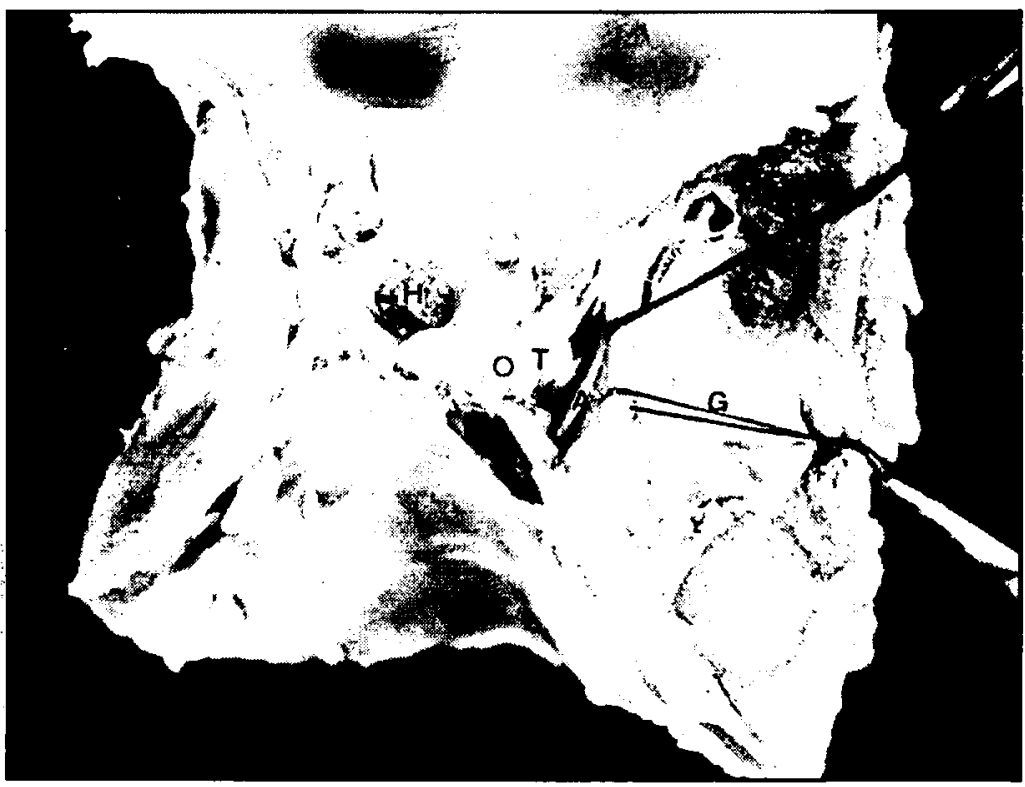

Fig I. Seio cavernoso. Disseçcão sob lupa das paredes posterior e lateral (tracionada) mostrando a artéria carótida interna (seta), os nervos óculo-motor (o), troclear $(t) e$ abducente (a), a sela túrcica ( $h$ ) e o gânglio trigeminal ( $g$ ). Fotografado do natural. 


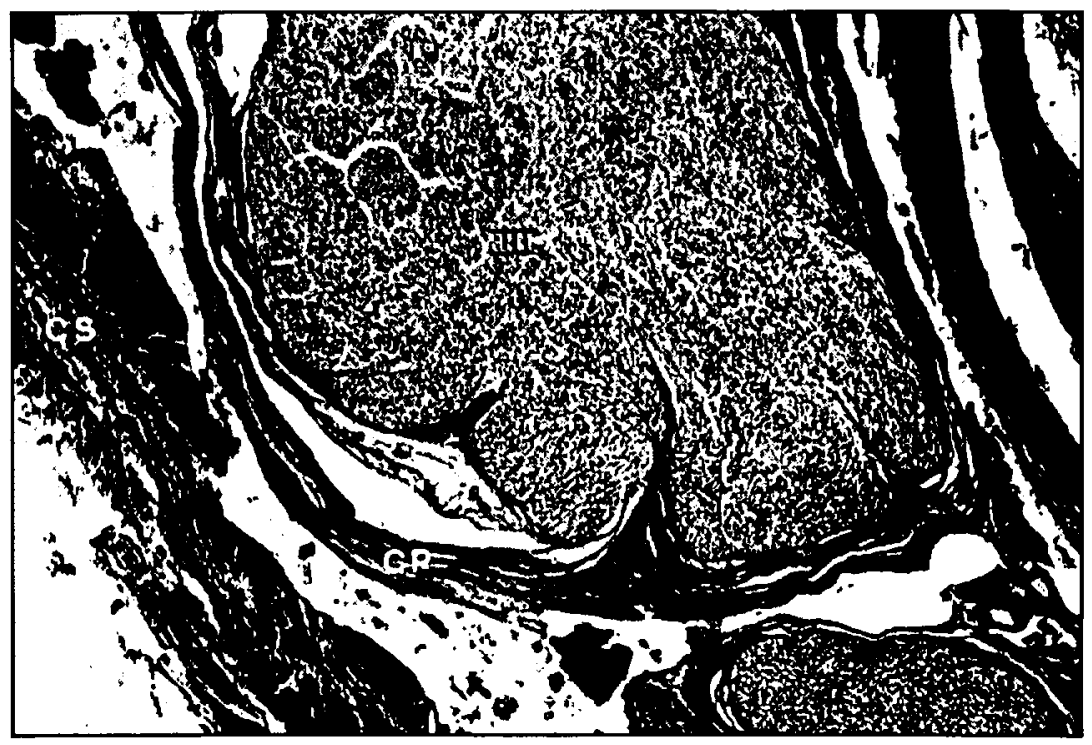

Fig 2. Seio cavernoso. Corte frontal (30 um) mostrando aspectos da parede lateral: camada superficial (cs), camada profunda (cp) e III (nervo óculo-motor). Azan, 16x.

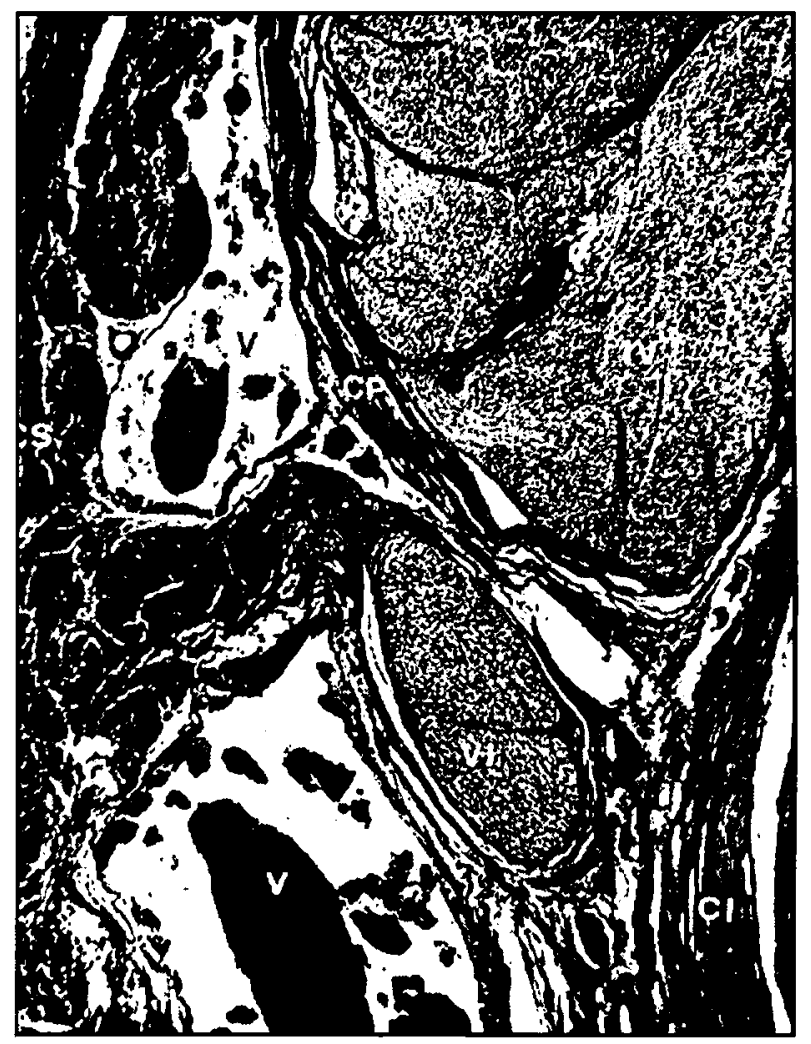

Fig.3. Seio cavernoso. Corte frontal $(30 \mathrm{um})$ mostrando a parede lateral: camadas superficial (cs) e profunda ( $c p$ ); nervos troclear (IV) e abducente (VI); artéria carótida interna $(C l) e$ espacos venosos (v). Azan 16x. 


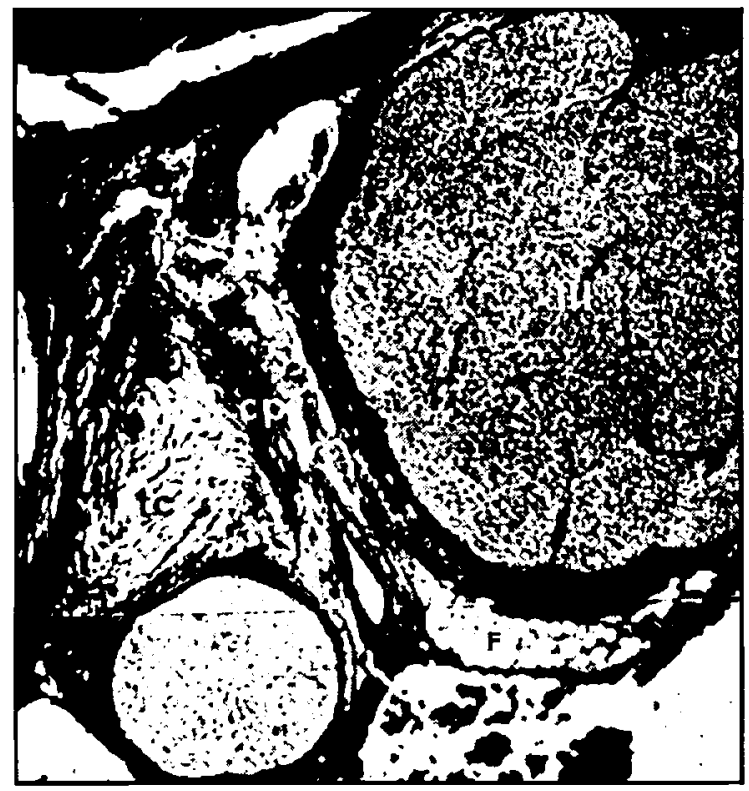

Fig 4. Seio cavernoso. Corte frontal ( 30 um) mostrando nervo óculo-motor (III). camada profunda da parede lateral (cp), tecido gorduroso $(f)$ e tecido conjuntivo frouxo (tc). Azan I6x.

o quinto inferior do seio esfenoidal; lateral, preservando-se a parede lateral do seio cavernoso e gânglio trigeminal (Fig 1).

Todas as peças obtidas foram fixadas em formaldeído a $10 \%$. Os blocos reduzidos foram a seguir submetidos a descalcificação em $\mathrm{HNO} 3$ a 10\%, processo que levou tempo médio de $\mathbf{3 0}$ a $\mathbf{4 0}$ dias. $O$ controle da descalcificação foi feito através de teste com oxalato de sódio a 5\%. Imediatamente após a descalcificação, os blocos foram lavados em soluçăo de sulfato de sódio a $5 \%$ por 24 horas e novamente colocados em solução de formaldeído a $10 \%$.

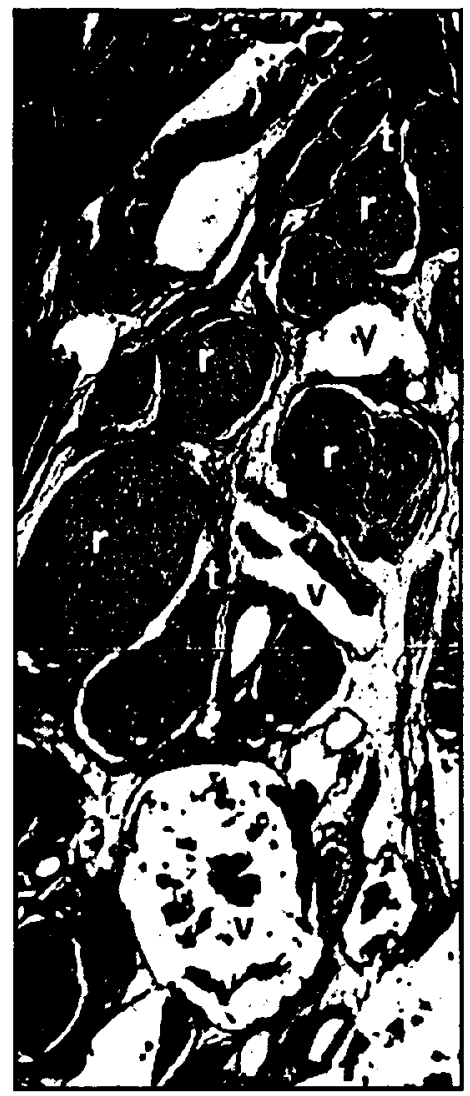

Fig 5. Seio cavernoso. Corte frontal ( 30 um) mostrando espaços venosos (v). ramos da divisão oftálmica do trigêmio (r) e trabéculas do tecido colágeno ( $t$ ). Azan \&x.

Os 15 blocos foram incluídos em parafina, para realização de cortes seriados espessos frontais de 30 micrômetros corados alternadamente e em sequência pelos métodos de Azan modificado por Heidenhain para evidenciar fibras colágenas e musculares, resorcina-fucsina Weigert para evidenciar fibras elásticas, ambos modificados por Dabelow e Ferraz de Carvalho. Os cortes seriados foram analisados através de lupa Zeiss SV 6 (FAPESP-91/2772-0) com aumento variando de 4 a 40x, posteriormente fotografados em fotomicroscópio Wild MPS 48 (FAPESP-92/3668-4).

Os outros 5 blocos restantes foram dissecados em microscópio cirúrgico Zeiss e a seguir fotografados no mesmo aparelho através de sistema fotográfico próprio.

\section{RESULTADOS}

As dissecçōes das peças ao microscópio cirúrgico evidenciaram duas camadas distintas na parede lateral do seio cavernoso, uma superficial e outra profunda, contendo os elementos nervosos já citados anteriormente, imbricados nos folhetos da dura-máter (Fig1). No interior da cavidade do seio, ao menos nas peças examinadas, não verificamos trabeculado denso, mas sim disperso, que às vezes se ligava à adventícia da carótida interna. Este trabeculado é mais evidente medialmente ao 


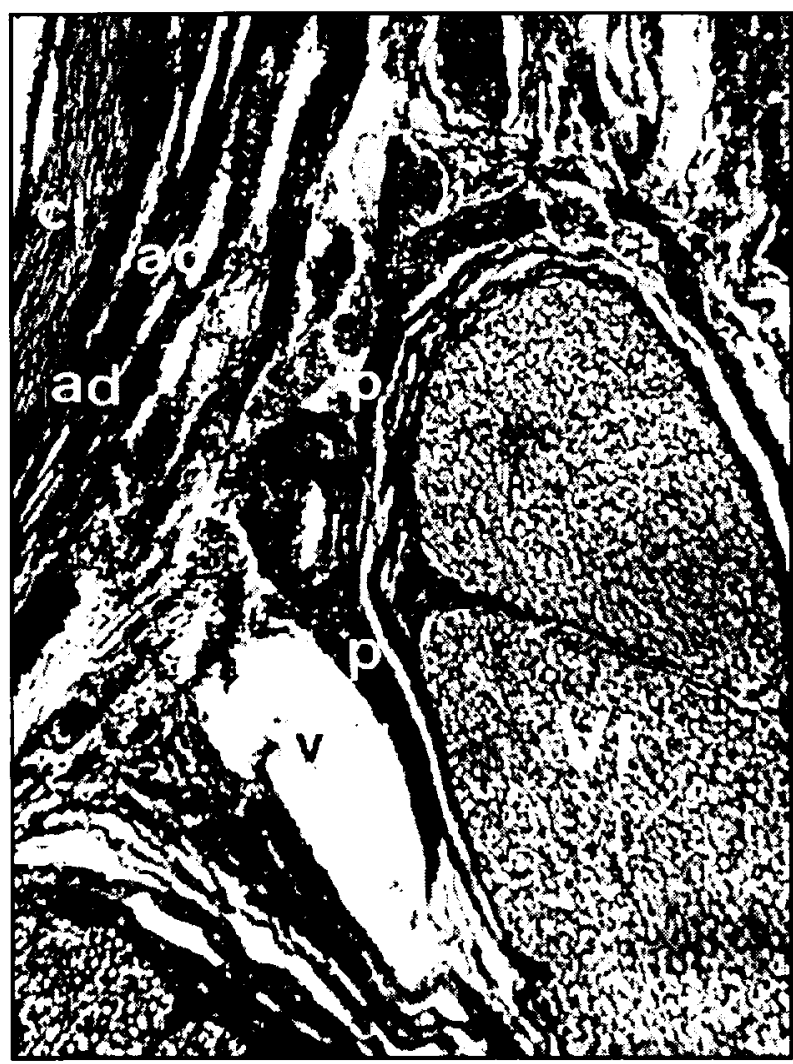

Fig.6. Seio cavernoso. Corte frontal (30 um) mostrando nervo abducente (VI) e seu perineuro ( $p$ ), artéria carótida interna (ci) e sua adventícia (ad). Observar espaf̧os venosos (v). Azan 16x.

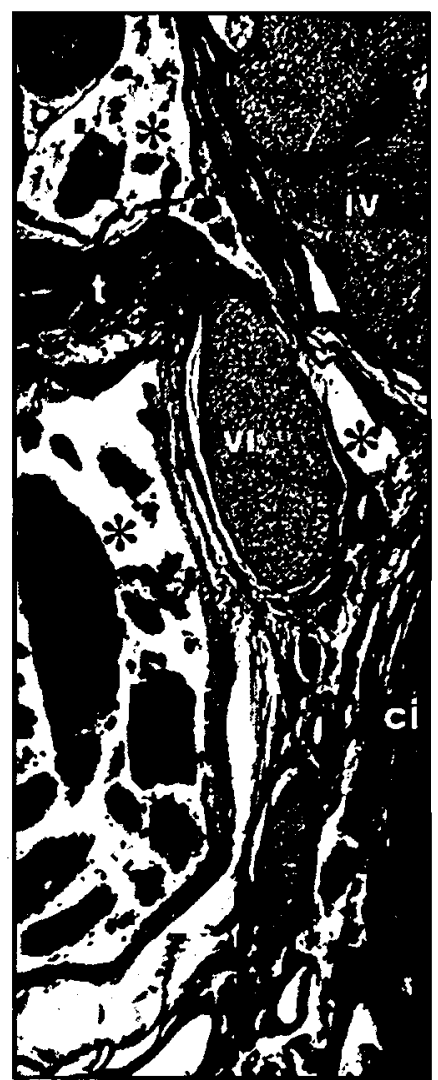

Fig 7. Seio cavemoso. Corte frontal ( 30 um) mostrando espaços venosos( $(*)$, antéria carótida intema (ci) e trabéculas de tecido colágeno (t). Azan $8 x$.

vaso no interior do seio cavemoso onde, nesta mesma cavidade, observamos que o nervo abducente tem íntima relaçāo com a parede mais lateral da carótida interna, quando no interior do seio; da mesma forma, o nervo craniano VI é melhor observado através da parede posterior; fica claro na abordagem do seio cavemoso pela parede posterior que o nervo craniano VI está separado da parede lateral e situado no interior da estrutura venosa (Fig1).

A análise dos cortes seriados espessos através da microscopia optica convencional evidenciou a seguinte arquitetura da parede lateral do seio cavernoso: uma camada superficial constituída da dura-máter e camada profunda de tecido conjuntivo frouxo, envolvendo os nervos III, IV, V1 (Figs 2 e 3). As duas camadas apresentam características morfológicas distintas, sendo a profunda irregular, ao contrário da camada superficial, que apresenta feixes de fibras espessas e compactas (Fig 2). 0 tecido colágeno da camada profunda constitui o perineuro dos nervos cranianos que por ali passam (Fig 4), envolvendo-os entre si e formando um estojo conjuntivo que se encontra septado por trabéculas de feixes colágenos delimitando espaços venosos em seu interior (Fig 5). $\mathrm{O}$ perineuro do nervo abducente apresenta-se contíguo à adventícia da artéria carótida interna no interior do seio cavernoso (Figs 6 e 7). Foi verificada a presença de coxins de tecido gorduroso na cavidade do seio cavernoso (Fig 4 ). As bainhas dos nervos III e V1 são mais espessas, e a do IV é mais fina e pouco evidente. 


\section{DISCUSSÃO}

Os textos clássicos de anatomia descrevem que os nervos III, IV e VI estão presentes na parede

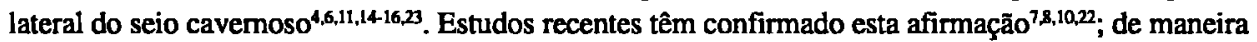
geral, nossos achados são idênticos.

Nossos resultados são semelhantes aos de outros autores ${ }^{2,12.18,19}$, quando descrevem a parede lateral do seio formada por duas camadas; ressaltamos porém, que ao contrário desses autores, encontramos os nervos III, IV e V1 num estojo de tecido conjuntivo, profundamente localizado, distinto do tecido conjuntivo superficial. Tal como outros ${ }^{14,19,23}$, encontramos as bainhas dos nervos que formam a camada profunda, ressaltando ainda que, nesta camada, existem feixes de fibras colágenas interpostas entre as bainhas nervosas, formando trabéculas que delimitam espaços venosos.

Ao contrário de Harris \& Rhoton 7 , e, mais recentemente, de Rhoton et al. ${ }^{12}$, nāo consideramos a camada profunda apenas um revestimento delgado de dura-matér, mas sim uma camada com características morfológicas distintas. Discordamos também de Umansky \& Nathan ${ }^{22}$, pois encontramos a camada profunda não apenas separando o seio em dois compartimentos, mas apresentando em seu interior espaços venosos menores; para eles, a camada profunda é constituída da bainha dos nervos e de membrana reticular que consideram incompleta, entre os nervos III e IV, e entre os nervos IV e V1.

Encontramos, ainda, a camada profunda formando um compartimento venoso evidente, adjacente à camada superficial, sendo limitado superiormente pela bainha do nervo óculo-motor, inferiormente pela divisão oftálmica do trigêmio e medialmente pelos nervos troclear e abducente. Como a maioria dos autores, encontramos o nervo abducente próximo à artéria carótida interna. Como Parkinson ${ }^{9}$ encontramos, no espaço profundo do seio cavernoso, tecido gorduroso formando coxins de sustentacão.

\section{CONCLUSÕES}

A parede lateral do seio cavemoso é formada por duas camadas: uma superficial e outra profunda, contendo esta última os nervos óculo-motor, troclear e divisão oftálmica do trigêmio.

O nervo abducente não está localizado no seio cavernoso junto aos outros nervos cranianos, mas sim próximo à parede lateral da artéria carótida interna.

A divisão maxilar do nervo trigêmio não está contida na parede lateral do seio cavernoso.

No espaço profundo do seio cavernoso foi verificada a presença de tecido gorduroso, formando coxins de sustentação.

\section{REFERENCIAS}

1. Bonnal J,Thibaut A, Brotchi J. Invading meningiomas of the sphenoid ridge. J Neurosurg 1980;53:587-599.

2. Bonnet P. La loge caverneuse et les sindromes de la loge caverneuse. Arch Ophthalmol (Paris) 1955;15:357-372.

3. Butler $H$. The development of certain human dural venous sinuses. J Anat 1957;91:510-526.

4. Crafts RD. A textbook of human anatomy. Ed2. New York: John Wiley \& Sons, 1979:503-505.

5. Dolenc V. Direct microsurgical repair of intracavernous vascular lesions. J Neurosurg 1983;58:824-831.

6. Gardner E, Gray DJ, O'Rahilly R. Anatomy: a regional study of human structure.Ed4. Philadelphia: Saunders:1975: 609-610.

7. Harris FS, Rhoton AL Jr. Anatomy of the cavernous sinus: a microsurgical study. J Neurosurg 1976;45:169-180.

8. McGrath P. The cavernous sinus: an anatomical survey. Aust NZ J Surg 1977;47:601-613.

9. Parkinson D. Surgical anatomy of the lateral sellar compartment (cavernous sinus). Clin Neurosurg 1990;36:219-239.

10. Patouillard P, Vanneuville G. Les parois du sinus caverneux. Neurochinurgie 1972;18:551-560.

11. Paturet G. Traité d'anatomie humaine. Vol.4 Paris: Masson. 1964;721-722.

12. Rhoton AL Jr, Hardy DG, Chambers SM. Microsurgical anatomy and dissection of the sphenoid bone, cavernous sinus and sellar region. Surg Neurol 1979;12:63-104.

13. Ridley H. The anatomy of the brain. London: Smith \& Walford: 1965:39-40.

14. Romanes GJ. Cunningham's textbook of anatomy. Ed12. London: Oxford Univ Press 1981;953.

15. Rouvière H. Anatomie humaine descriptive et topographique. Ed10. Paris. Masson 1970:678.

16. Sinelnikov PD. Atlas of human anatomy. Moscow: Izdatelstvo Meditsina, 1958:2154. 
17. Snell RS. Clinical anatomy for students. Ed2. Boston. Little Brown, 1981:43.

18. Taptas JN. L'artère carotide interne dans son parcours intra-crânien: particularités anatomiques, implications cliniques. J Chir (Paris) 1981;12:719-723.

19. Testut L, Latarjet A. Tratado de anatomia humana. Vol.2 Barcelona: Salvat. 1974:441.

20. Thompson JS. Core textbook of anatomy. Philadelphia: JB. Lippincott: 1977;204-206.

21. Thorek P. Anatomy in surgery. Philadelphia: Lippincott, 1951:58.

22. Umansky F, Nayhan $H$. The lateral wall of the cavernous sinus with special reference to the nerves related to it. J Neurosurg 1982;56:228-234.

23. Warwick CK. Willians PL (eds.) Gray's Anatomy. Ed 35. Edinburgh: Lomgman, 1973:695.

24. Weinberger LM, Adler FH, Grant FC. Primary pituitary adenoma and the syndrome of the cavernous sinus: a clinical and anatomic study. Arch Ophthalmol 1940;2:1196-1236.

25. Winslow JB. Exposition anatomique de la structure du corps humain. Vol.2 London; Prevost, 1732:31.

26. Zozulia YA, Romodanov SA, Patsko YV. Diagnosis and surgical treatment of benign craniobasal tumours involving the cavernous sinus. Acta Neurochir 1979;28(Suppl):387-390. 